\title{
Proactive Student Engagement with Fitness to Practise
}

\author{
Kristin Lo, ${ }^{1}$ Stephen Maloney, ${ }^{1}$ Margaret Bearman, ${ }^{2}$ and Prue Morgan ${ }^{1}$ \\ ${ }^{1}$ Department of Physiotherapy, Monash University, Melbourne, Australia \\ ${ }^{2}$ HealthPEER, Monash University, Melbourne, Australia \\ Correspondence should be addressed to Kristin Lo; kristin.lo@monash.edu
}

Received 4 April 2014; Accepted 29 June 2014; Published 15 July 2014

Academic Editor: Chandrashekhar T. Sreeramareddy

Copyright (C) 2014 Kristin Lo et al. This is an open access article distributed under the Creative Commons Attribution License, which permits unrestricted use, distribution, and reproduction in any medium, provided the original work is properly cited.

Fitness to practise (FTP) is fundamental to health professional education and health service delivery, impacting on both practitioner and client wellbeing. Literature exploring FTP support policies primarily identifies retrospective student support and management. This study describes student perceptions of an innovative FTP policy which supports students and staff to proactively identify FTP management strategies prior to entering the clinical environment. Forty-nine final year physiotherapy students were surveyed regarding their perceptions of self-declaring FTP. Ordinal data from Likert scales were reported using descriptive statistics. Thematic analysis was undertaken for open text responses. The response rate was $88 \%$. Forty-two percent of students stated that they had experienced FTP concerns during the course. Concerns included physical and mental impairment and clinical competence issues. The majority of students $(80 \%)$ indicated that they were "comfortable" or "very comfortable" in self-declaring FTP issues. Confidentiality, positive relationships with staff and a supportive environment enhanced likelihood of declaration. Eight students (19\%) met with university staff to develop management strategies and all rated these meetings as "helpful" or "very helpful." Students had positive perceptions of self-declaring their FTP to enable early development of management strategies. This strategy successfully navigates sensitive ethicolegal issues, empowering students to take responsibility for their own FTP.

\section{Introduction}

Fitness to practise (FTP) can be defined as a person's ability to practise their profession, meeting appropriate standards. This includes the practical skills, inherent knowledge, attitudes, personal characteristics, and health to perform necessary functions both effectively and safely [1]. Whilst evidence on strategies to support FTP has not yet emerged in the physiotherapy profession, literature from other health professions indicates that university FTP support policies focus on identification and remediation of students who exhibit unprofessional behavior [2-7].

FTP is a broader term than professionalism, as professionalism is often contingent upon freedom from other impairments. Parker [8] described FTP as having three specific components: (1) "freedom from impairment" (physically and mentally fit to perform duties), (2) "professional conduct and behavior" (meets appropriate codes of conduct and ethical guidelines), and (3) "clinical competence" (demonstrates adequate skills and knowledge).

Health professional students within clinical environments must adapt to varying teaching styles, new health services, and data from numerous sources all whilst seeking to improve their practice and making competent decisions regarding their clients' health. The physical and psychological demands involved are considerable and may impact negatively upon healthcare provider health and wellbeing. This impact is well documented among the medical student and practitioner fraternity [9-11] with similar trends observed in clinicians across other health professional disciplines including physiotherapy $[12,13]$. Physical wellbeing is particularly important to physiotherapy practitioners where physical limitations may significantly impact their ability to implement treatments and provide physical support to patients. 
Impaired FTP may reduce patient safety, student safety, effectiveness of patient interventions, and educational value of the clinical experience. This is particularly relevant in a climate where clinical placements are in significant demand due to increasing student numbers and university competition for limited resources [14]. Consequently, impaired student FTP not only can result in lost clinical education hours from student illness or unsatisfactory placement outcomes, but also may jeopardize the relationship between clinical educators and the university.

Research specifically into medical student performance indicates that the factors contributing to impaired FTP are multifactorial. Seritan et al. [11] summarizes these factors as (1) "intrapersonal", including medical/mental health, academic and emotional intelligence issues, and personality factors, (2) "interpersonal," such as work-life balance, personal life events, and financial stress, and (3) "institutional," pertaining to interactions with peers and staff, student mistreatment, and exposure to human suffering. Kernan et al. [15] propose that interpersonal issues and psychological factors are both extremely prevalent and have the most significant negative impact on student academic performance. They advocate forming effective partnerships between academic and student support services to mitigate risk and identify support strategies. Cleland et al. concurs, suggesting that early intervention may prevent the student experiencing a "cycle of failure" [16].

Driven by the need to manage "issues of unprofessional medical student conduct and behaviour," McGurgan et al. [2] report on a survey of Australian medical school FTP policies. The policies described align with eight criteria including concerns regarding criminal activity, drug or alcohol consumption, fraudulent activity, unprofessional behaviors including plagiarism, and the insight and/or management of health concerns. These criteria emphasize retrospective identification. That is, policies will, for the most part, identify students once they have breached what is regarded as "professional" conduct. There are few, if any, programs which report assisting "at risk" students prior to clinical placements thus preventing any potential unprofessional behavior. This may be due to apprehension from educational institutions in navigating the complex ethical, legal, and process issues involved in deliberately probing for sensitive information. Additionally, as Devereux et al. [17] identify, students may lack information as to what might potentially impair their practice and may be concerned that disclosure may prevent their academic progression.

We contend that proactive management of students with FTP issues, prior toentering clinical environments, has significant advantages. This type of management strategy creates a supportive learning environment for students in the potentially stressful transition to work-based learning and may positively impact on patient safety through reducing the risks of "unsafe" students. Additionally, a self-disclosure approach requires students to model self-regulatory behavior; taking responsibility for their own health, wellbeing, and professionalism are critical requirements of working as a healthcare professional.
The aim of this paper is to explore students' acceptability of a proactive FTP policy. The specific research question was how do students respond to a model where students declare and are responsible for managing their own FTP?

\section{Method}

2.1. Educational Context. The Monash University Bachelor of Physiotherapy is a four-year undergraduate program. The theoretical and practical curriculum are fully integrated both horizontally and vertically, spanning both core (cardiorespiratory, musculoskeletal, and neurological) and specialty areas of practice.

A proactive self-declarative approach to FTP was designed and implemented, working closely with legal representatives and stakeholders from student support networks. All physiotherapy students, prior to the commencement of clinical placements each year, disclose whether they do or do not wish to discuss any physical, mental, or emotional issue that may impact upon their FTP. Students indicating that they wish to discuss a FTP issue are offered a meeting with a physiotherapy department academic staff member. This meeting incorporates the techniques of motivational interviewing to promote behavior change [18]. The aim of this meeting is not to prevent participation in the clinical environment but to identify any factors that may impact on student learning. This enables university staff to discuss and/or facilitate proactive implementation of student-centered management strategies to assist students to optimize their FTP. This may include referrals to services including learning skills support, counseling, and financial support where indicated.

2.2. Design. This is a cross-sectional study incorporating data gained from anonymous student surveys.

2.3. Process. Following approval by the Monash University Human Research Ethics Committee (CF10/1321-2010000703) a cohort of 49 final (fourth) year undergraduate physiotherapy students were invited to complete a survey immediately prior to graduation (week 12 semester 2), 2011, regarding their experiences of the piloted self-declaration of FTP (Appendix) that constitutes part of the Physiotherapy Department's FTP policy.

The student survey contained nine items regarding FTP (Box 1). Level of agreement to the items was rated on a five point Likert scale from "very unhelpful" (1) to "very helpful" (5) or "very uncomfortable" (1) to "very comfortable" (5).

2.4. Data Analysis. Ordinal data from Likert scale responses are reported using descriptive statistics. Free text data are clustered by question topic. A basic thematic analysis approach was undertaken [19]. Counting of responses was completed where relevant and illustrative quotes were selected to represent students' perceptions. 
(Q1) According to Parker's definition of "fitness to practice", have you ever been concerned about your own fitness to practise?

(Q2) What broad areas might these be around? (free text)

(Q3) Did you feel comfortable declaring any health issues or other condition that you believed might affect your ability to participate in clinical education and discussing this with a Unit coordinator/staff member? (Likert scale: $1=$ very uncomfortable to $5=$ very comfortable)

(Q4) What made you feel comfortable/uncomfortable about checking the declaration box on the FTP form? (free text)

(Q5) Do you have any recommendations for changes to the current form?

(Q6) If you attended, a FTP meeting with a University staff member, how did you find this meeting? (Likert scale: $1=$ Very unhelpful to $5=$ Very helpful).

(Q7) In what ways did you find this meeting helpful? (free text)

(Q8) In what ways did you find this meeting unhelpful? (free text)

(Q9) Do you have any suggestions about how we might have made recognizing and taking advantage of University support easier for you? (free text)

Box 1: Survey items.

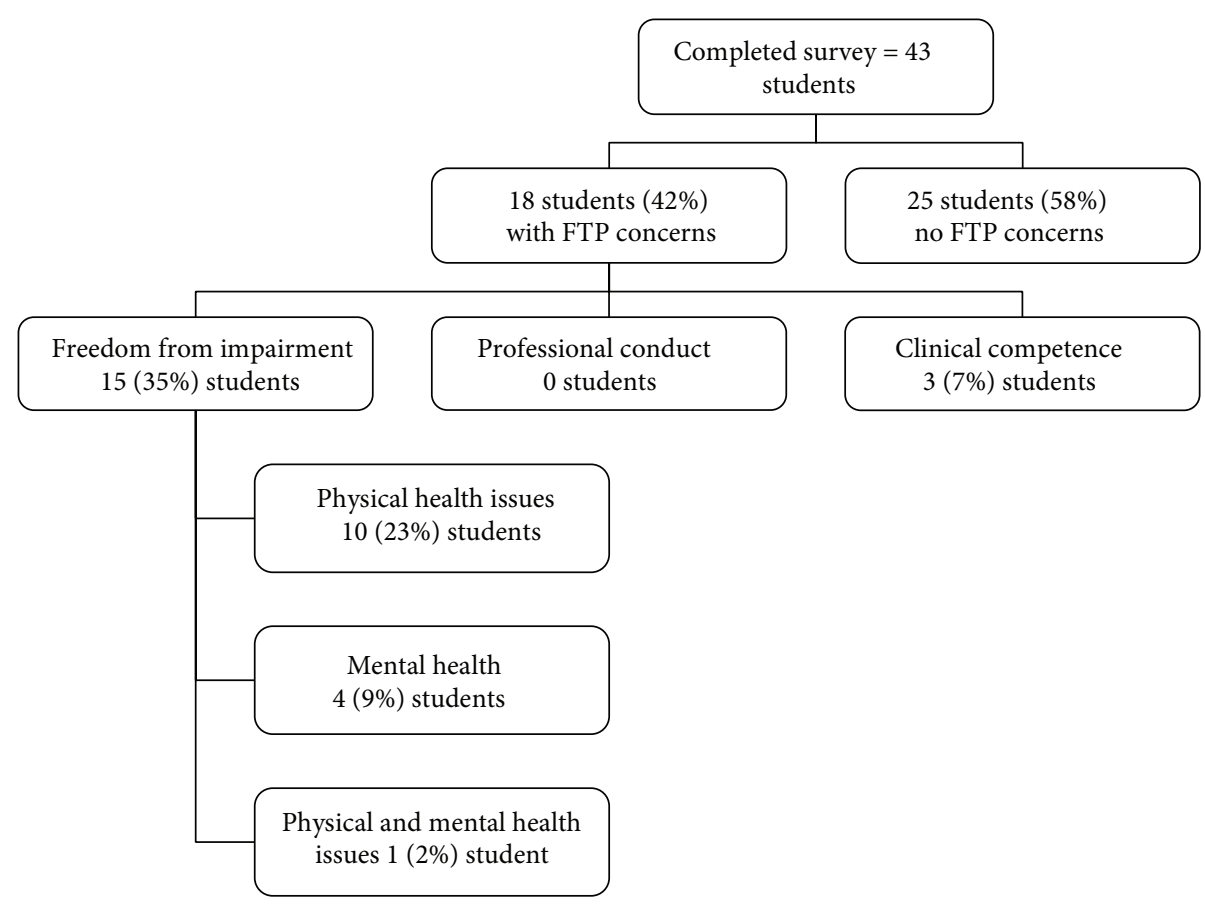

FIGURE 1: Flow chart including summary of FTP concerns identified in survey responses.

\section{Results}

Forty-nine final year physiotherapy students were surveyed regarding their perceptions of self-declaring FTP with a response rate of $88 \%(43 / 49)$. Eighteen of 43 (42\%) respondents stated that, according to Parker's definition [8], they had been concerned about their FTP (Figure 1).

Thirty four of $43(80 \%)$ students declared themselves "comfortable" or "very comfortable" in declaring FTP issues. Eight $(8 / 43,19 \%)$ students attended FTP meetings and 100\% or 8/8 declared them "helpful" or "very helpful" (Table 1 ).

The comment analysis is presented by groups aligned with the free-text questions.

\subsection{Areas of FTP Concern}

3.1.1. Freedom from Impairment. Fifteen (15/43, 35\%) students discussed impairment issues such as physical health including injury and fatigue (10 students), mental health including stress (4 students), and both physical and mental health issues (1 student). As expected, 5/43 students commented that they felt comfortable in declaring health issues as they considered themselves healthy: "I do not have any issues so have no issue in feeling comfortable to say so" (student 35 ).

3.1.2. Professional Conduct. No students highlighted professional conduct issues. 
TABLE 1: Proportion of respondents regarding comfort in declaring FTP and experience of FTP meetings.

\begin{tabular}{lc}
\hline Survey item & Proportion of respondents \\
\hline Comfort in declaring FTP issues & \\
Very uncomfortable & $0 / 43(0 \%)$ \\
Uncomfortable & $4 / 43(9 \%)$ \\
Neutral & $5 / 43(12 \%)$ \\
Comfortable & $17 / 43(40 \%)$ \\
Very comfortable & $17 / 43(40 \%)$ \\
Experience of FTP meeting & \\
Very unhelpful & $0 / 8(0 \%)$ \\
Unhelpful & $0 / 8(0 \%)$ \\
Neutral & $0 / 8(0 \%)$ \\
Helpful & $4 / 8(50 \%)$ \\
Very helpful & $4 / 8(50 \%)$ \\
\hline
\end{tabular}

3.1.3. Clinical Competence. Three students indicated clinical competence issues regarding future interactions with clients and "concerns about having the appropriate skills" (student 10).

3.2. Comfort with Reporting FTP. Numerous students (25) reported specific institutional (university) enablers, which made them feel comfortable to declare FTP issues. Overwhelmingly students stated that confidentiality and a positive relationship with staff in relation to trust, familiarity, rapport, and willingness to help increased their comfort to declare FTP issues. Student 31: "I trusted and felt able to approach the staff who would be dealing with any concerns raised." One student stated that they might retract their desire to discuss issues if they did not feel comfortable with the staff member.

There were three student comments regarding barriers to disclosing FTP issues including the potential to have their views doubted, skills prejudged, and concern about being unable to participate in clinical placements. Student 24 stated "I was unsure as to whether this might give my supervisor or the university preconceived ideas regarding my abilities."

3.3. Experience of the FTP Meetings. The students who attended the FTP meetings described the meeting as helpful to screen concerns, discuss options, and outline ideas for improvement and possible strategies to prevent/remedy issues if they should arise. Factors describing the supportive nature of academic staff were evident. Student 11 stated that academic staff were "considerate, caring, friendly, and approachable." Reflections on the experience of the meeting included the following:

\section{"I was very clear on the possible options should my situation change or become worse during place- ment. We also discussed management options to adopt whilst I was on placement. I left the meeting feeling very well supported by the university" (student 36).}

Student 18 found the meeting helpful, however also stated that it was "intimidating."
3.4. Further Suggestions regarding Proactive Management of FTP. Students made a number of suggestions as to how to enhance understanding and recognition of their own FTP and improve access to available support. Key suggestions included regular email contact between staff and students to see how they are coping with placements (particularly in rural areas) and reminders to students regarding FTP throughout the year as these issues may develop over the duration of clinical education. Open and honest declaration could be encouraged by providing examples of previous scenarios that have arisen and the strategies implemented to successfully support students. Student 24 highlighted the need for the university to clarify that "...by identifying an area that the student feels should be discussed, it does not mean that they are "unfit" to be a physiotherapist." Students wanted reassurance that declaring FTP issues would not result in cancellation of a placement and that measures would be taken to minimize the likelihood of placement interruption.

\section{Discussion}

In a climate where educational research focuses on retrospective student support and management, primarily of professionalism issues, these results demonstrate that students are prepared to self-declare FTP issues prior to entering the clinical environment. A sizable proportion of students (18/43 or $42 \%$ ) declared FTP concerns, illustrating the necessity of an approach to support FTP. However, it is interesting to note that only $8 / 43$ were prepared to formally declare these concerns, particularly when 15 of the cohort cited physical or mental health concerns. These causes of student "distress" are reflected in the health science literature and highlight the importance of implementing strategies to support FTP [20-25]. While clinical competence issues can be addressed during coursework components of the university program, ensuring appropriate physical and mental health status is significantly more challenging.

In this cohort there were a number of physical health issues $(11 / 43,26 \%)$. Half of these were injury related; however, it is not known whether they were work-related musculoskeletal disorders (WMSD) or injuries acquired outside of studies. Literature describes physiotherapists as being unlikely to officially report physical injury and this may be reflected in our data $[26,27]$. While the causes of these injuries remain unknown, injury is of significance to the physical demands of the physiotherapy profession. The 12month incidence rate of WMSD in physiotherapists varies and has been reported by Glover et al. [28] as 20.7\%. Often the first episode of WMSD occurs within the first few years of practice or among younger therapists [26, 27], highlighting the importance of interventions to address physical health issues in student physiotherapists [26].

The incidence of stress/mental health issues in the cohort was mentioned by $5 / 43(12 \%)$ respondents. While this is considerably lower than the national average prevalence of mental health disorders in this age group reported to be $26 \%$ in 16-24 year olds [29], this is a significant proportion of respondents and highlights the need for strategies to 
manage potential stress/psychological/emotional issues in the university curriculum. This view is supported by research revealing that medical students exhibit disproportionate levels of stress related impairment with prevalence rates of mental health symptoms reaching as high as $25 \%$ to $56 \%$, depending on the study methodology [21]. Mental health and interpersonal issues are amongst the most prevalent student health concerns and are perceived by medical students to account significantly for adverse academic consequences [15]. Consequently, medical schools have been urged to emphasize to students the importance of strategies to optimise health, maintain social and personal lives whilst pursuing their studies [30], and cultivate resilience [31]. Authors have also highlighted the importance of introducing curricula on wellbeing including strategies for self-help complemented by "adequate and well-promoted support services" [9]. The FTP support meetings aim to promote these findings. While in our cohort the incidence of physical health limitations outweighs the incidence of mental health issues, it is likely that there is underreporting. Devereux [17] indicated that students are less likely to disclose health impairments such as mental health issues due to a perceived stigma.

The role of interpersonal factors in FTP is less pervasive but this may be the limitation of the survey format as much as an absence of factors. In our results, it is difficult to determine whether mental health, stress, and fatigue issues are a consequence of underlying work-life balance issues. Literature demonstrates that work-life balance and burnout issues are prominent in both undergraduate student cohorts and new graduates [12, 21-23].

Institution-specific factors seem to be important in determining how confident students feel to disclose issues. Comfort appears to increase when the following factors are in place: confidentiality, positive relationships with staff members, and a supportive environment, with $80 \%$ of respondents to this survey item being either "comfortable" or "very comfortable" with declaring FTP issues. This is supported by Roberts et al. [32] who demonstrated that concerns of confidentiality significantly affect student disclosure of health issues. It must be noted however that four respondents did not respond to this survey item and four respondents felt "uncomfortable" which indicates that not all students responded positively to the self-declaration. Students suggested that confidence could be further improved with education dispelling concerns about the consequences of declaring FTP issues on clinical practice. These ideas are reflected in the literature with medical students indicating concerns about confidentiality and a fear of academic and other negative professional repercussions as significant barriers to seeking care [32].

The student support meetings appear to be beneficial as all students attending the FTP meetings found them "helpful" or "very helpful." Analysis indicates that the important facets of these meetings include providing students with a forum in which to discuss any issues that impact on their education and proactively discussing options and management strategies in a considerate and approachable manner. The FTP meetings provide a forum for a student-centered approach to introduce the various support services available. This supports Schweitzer [33] who noted that students have poor knowledge of the resources available within Australian universities, particularly in areas of high prevalence that could benefit from support such as emotional issues. Schweitzer suggests that strategies addressing this lack of awareness would help Australian universities "achieve their goals... of a more diversified student population” [33]. Approaches such as these may also help to ensure a more diverse population of healthcare professionals.

The data indicate that students primarily perceive FTP as relating to freedom from impairment issues. However, it is important to note that, in Parkers' tripartite approach to FTP, freedom from impairment, professionalism issues, and clinical competence is directly interrelated. Consequently, an understanding of impairment is imperative to fully elucidate all dimensions of FTP issues and this innovative FTP process models the type of self-declaration required to fully examine all attributes of FTP.

There are a number of limitations to this study. Selfreport may misrepresent real FTP issues as students may not understand their own limitations, particularly pertaining to competence or professionalism; on the other hand the anonymous format of the survey has assisted in identifying individuals that had FTP concerns but did not nominate to attend a meeting. Other limitations may impact on the transferability of a self-declarative FTP scheme from one institution to others' contexts. Characteristics of the student cohort, the individual staff, and the institutional environment may influence the success of the scheme in varying contexts.

It is essential to consider why at least 10/18 students did not attend a meeting-despite declared comfort-in order to receive the necessary support. This may be due to a reluctance to declare issues through fear of consequences. We attempted to ameliorate this, through providing students with detailed information on what constituted FTP issues and emphasizing the supportive rather than punitive nature of the process. Future research directions include unpacking the successful components of the support meetings such as describing the process and the characteristics that foster a positive relationship with university staff members, as these are significant factors influencing students' comfort to disclose FTP issues. The cost-benefit of providing FTP meetings, with respect to time input from clinical and academic staff to support students within the clinical setting and the alterations to student clinical progression that occur due to FTP issues, would also be worthy of investigation.

\section{Conclusions}

To our knowledge, this study is the first to examine FTP support strategies in physiotherapy students. This study illustrates a student-centered approach to FTP and indicates that a FTP policy involving self-declaration of FTP issues can be positively received by students. A proactive policy promotes learner independence and highlights the importance of transparency and collaboration as key components of personal and professional development. 
TABle 2: Physical, mental, and emotional demands of undergraduate (campus-based and clinical) physiotherapy course.

\begin{tabular}{|c|c|}
\hline $\begin{array}{l}\text { Physical demands } \\
\text { (including mobility } \\
\text { requirements): }\end{array}$ & $\begin{array}{l}\text { (i) Implement manual handling and risk minimization procedures applicable to the task } \\
\text { (ii) Demonstrate physical ability to carry out physiotherapy assessment and intervention including responsible } \\
\text { manual handling of peers and patients, facilitating body position changes, assisting with mobilization ( } \pm \text { gait } \\
\text { aids), leading, and participating in group exercise classes (including warm up, stretches, circuits, etc.) } \\
\text { (iii) Demonstrate ability to apply a range of treatment techniques including mobilisation, exercise, and } \\
\text { electrophysical agents }\end{array}$ \\
\hline $\begin{array}{l}\text { ty } \\
\text { ements }\end{array}$ & $\begin{array}{l}\text { (i) Demonstrate skills required for assessment and management of patients across the core areas of practice, } \\
\text { cardiorespiratory, neurological, musculoskeletal, as well as in pediatrics, gerontology, and aquatic physiotherapy } \\
\text { (ii) Undertake clinical education in allocated locations, including rural sites }\end{array}$ \\
\hline Mental demands: & $\begin{array}{l}\text { (i) Conduct sensitive and systematic patient interviews, and accurately record interview findings } \\
\text { (ii) Demonstrate professional conduct across a spectrum of challenging clinical circumstances such as during } \\
\text { supervised practise, when patients exhibit distress and during periods of heavy workload } \\
\text { (iii) Manage time effectively, balance work, study, and rest } \\
\text { (iv) Deliver coherent public presentations } \\
\text { (v) Work effectively with challenging patient groups such as people with dementia, patients who may be } \\
\text { uncooperative or abusive and patients with mental and/or physical disabilities, substance abuse, terminal } \\
\text { illness, and so forth } \\
\text { (vi) Work effectively with individuals from different cultures, race, linguistic background, age, gender, and } \\
\text { disability } \\
\text { (vii) Perform and complete designated tasks in a professional manner } \\
\text { (viii) Where appropriate, seek help in a timely fashion }\end{array}$ \\
\hline Emotional demands: & $\begin{array}{l}\text { (i) Ability to process and discuss distressing information with patients and caregivers, for example, poor } \\
\text { outcome/lifelong disability } \\
\text { (ii) Provide treatment of terminally or critically ill patients (including in a hospital setting) } \\
\text { (iii) Deal constructively with emotional patients and patients who have sensitive needs and/or require an } \\
\text { empathetic approach } \\
\text { (iv) Deal constructively with clinical educator advice and feedback } \\
\text { (v) Carry out potentially distressing treatments such as suctioning }\end{array}$ \\
\hline
\end{tabular}

\section{Appendix}

\section{Practical Considerations for Clinical Components of the Bachelor of Physiotherapy}

Work in the field of Physiotherapy has a high level of physical, mental, and emotional demands. A description of the usual demands is set out in the attached schedule (Table 2) which students are required to read and carefully consider.

Students are likely to experience these demands during campus based practical classes and during compulsory clinical placements. To maximize the chances of successful practical classes and placements and to minimize the risk of injury to students and any other persons (including clinical placement clients) it is essential that we know in advance if a student has any health, medical, or disability issues with the potential to affect their ability to perform practical skills or placement duties.

Monash is committed to ensure its students that are given every opportunity to demonstrate their abilities in all areas. The Department of Physiotherapy seeks information from its students to assist them to participate safely in all courserelated activities. As an example, sometimes a relatively minor adjustment to working conditions can have a profound benefit for a student who might otherwise face difficulties.

The university will not disclose a student's personal information to a placement provider without the student's consent or as permitted by privacy laws. In our experience, sharing limited information can, in some cases, assist the process of arranging appropriate placement conditions. If we perceive a potential safety risk with the placement of a particular student, we will discuss this with the student concerned as part of the process of approving their placement.

If you believe that you have a health or medical condition or disability that is likely to affect your ability to safely participate in the practical components of the course, our departmental clinical coordinator would like to speak with you about it and discuss ways to accommodate you safely within the program. Please return this form with your name and contact details completed. On your request, the clinical coordinator will contact you.

Student Declaration: I have read the list of physical, mental, and emotional demands of the undergraduate (campus based and clinical) physiotherapy course associated with the practical education components of the bachelor of physiotherapy at Monash University (Table 2). I declare that (please tick)

$\square$ I do not wish to discuss with department staff any health or other conditions that are likely to affect my ability to participate in this clinical education.

$\square$ I do have a health issue or other condition that I believe might affect my ability to participate in this clinical education and I would like to discuss this with a unit coordinator or other staff member. 


\section{Full Name:}

\section{Preferred Contact Details:}

For more information please contact your unit coordinator or any staff member involved in the program. Alternatively, the disability liaison officer and student counselors in health, wellbeing, and development can provide you with information and advice.

The information collected on this form and in any discussion prompted by submission of this form will not be used for purposes other than those outlined above, without your permission. You have a right to access personal information that Monash University holds about you, subject to any exceptions in relevant legislation. If you wish to seek access to your personal information or enquire about the handling of your personal information, please contact the university privacy officer.

\section{Conflict of Interests}

The authors declare that there is no conflict of interests regarding the publication of this paper.

\section{Acknowledgments}

The authors thank the physiotherapy students of Monash University and the Clinical Educators that support their students for their participation in this study. They also thank Professor Jenny Keating for her work on instituting the student self-declaration and Lynnette Denman for her assistance with data entry.

\section{References}

[1] Health Professions Council, Consultation on Student Fitness to Practise and Student Registration, HPC, London, UK, 2011.

[2] P. M. McGurgan, D. Olson-White, M. Holgate, and D. Carmody, "Fitness-to-practise policies in Australian medical schools-are they fit for purpose?" Medical Journal of Australia, vol. 193, no. 11-12, pp. 665-667, 2010.

[3] J. Aldridge, S. A. Bray, and T. J. David, "Medical student fitness to practise committees at UK medical schools," BMC Research Notes, vol. 2, article 97, 2009.

[4] E. Dean, "NMC to keep student records in bid to ensure fitness to practise," Nursing standard, vol. 25, no. 36, article 5, 2011.

[5] P. Duff, "Teaching and assessing professionalism in medicine," Obstetrics and Gynecology, vol. 104, no. 6, pp. 1362-1366, 2004.

[6] H. C. Gallagher, "New fitness-to-practice requirements for pharmacists in Ireland: implications for undergraduate pharmacy education," Medical Teacher, vol. 32, no. 2, pp. e71-e77, 2010.

[7] J. Morrison, "Professional behaviour in medical students and fitness to practise," Medical Education, vol. 42, no. 2, pp. 118-120, 2008.

[8] M. Parker, "Assessing professionalism: theory and practice," Medical Teacher, vol. 28, no. 5, pp. 399-403, 2006.

[9] J. M. Hillis, W. R. G. Perry, E. Y. Carroll, B. A. Hibble, M. J. Davies, and J. Yousef, "Painting the picture: Australasian medical student views on wellbeing teaching and support services," Medical Journal of Australia, vol. 192, no. 4, pp. 188190, 2010.

[10] L. Elliott, J. Tan, and S. Norris, The Mental Health of Doctors-A Systematic Literature Review, Beyondblue: The national Depression Initiative Australia, 2010.

[11] A. Seritan, J. Hunt, A. Shy, M. Rea, and L. Worley, "The state of medical student wellness: a call for culture change," Academic Psychiatry, vol. 36, no. 1, pp. 7-10, 2012.

[12] M. DiGiacomo and B. Adamson, "Coping with stress in the workplace: implications for new health professionals," Journal of Allied Health, vol. 30, no. 2, pp. 106-111, 2001.

[13] S. Scutter and M. Goold, "Burnout in recently qualified physiotherapists in South Australia," Australian Journal of Physiotherapy, vol. 41, no. 2, pp. 115-118, 1995.

[14] S. Rodger, G. Webb, L. Devitt, J. Gilbert, P. Wrightson, and J. McMeeken, "Clinical education and practice placements in the allied health professions: an international perspective," Journal of Allied Health, vol. 37, no. 1, pp. 53-62, 2008.

[15] W. D. Kernan, M. E. Wheat, and B. A. Lerner, "Linking learning and health: a pilot study of medical students' perceptions of the academic impact of various health issues," Academic Psychiatry, vol. 32, no. 1, pp. 61-64, 2008.

[16] J. Cleland, R. Arnold, and A. Chesser, "Failing finals is often a surprise for the student but not the teacher: identifying difficulties and supporting students with academic difficulties," Medical Teacher, vol. 27, no. 6, pp. 504-508, 2005.

[17] J. Devereux, P. Hosgood, J. Kirton, B. A. Jack, and A. M. Jinks, "Why do students fail to disclose health problems?" Nursing Times, vol. 108, no. 1-2, pp. 18-20, 2012.

[18] W. R. Miller, "Motivational interviewing with problem drinkers," Behavioural Psychotherapy, vol. 11, no. 2, pp. 147-172, 1983.

[19] C. Pope, N. Mays, and J. Popay, Synthesizing Qualitative and Quantitative Health Research: A Guide to Methods, McGrawHill International, Maidenhead, UK, 2007.

[20] L. N. Dyrbye, M. R. Thomas, and T. D. Shanafelt, "Medical student distress: causes, consequences, and proposed solutions," Mayo Clinic Proceedings, vol. 80, no. 12, pp. 1613-1622, 2005.

[21] L. B. Dunn, A. Iglewicz, and C. Moutier, "A conceptual model of medical student well-being: promoting resilience and preventing burnout," Academic Psychiatry, vol. 32, no. 1, pp. 44-53, 2008.

[22] L. N. Dyrbye, M. R. Thomas, J. L. Huntington et al., "Personal life events and medical student burnout: a multicenter study," Academic Medicine, vol. 81, no. 4, pp. 374-384, 2006.

[23] C. Gibbons, "Stress, coping and burn-out in nursing students," International Journal of Nursing Studies, vol. 47, no. 10, pp. 12991309, 2010.

[24] D. A. Reed, T. D. Shanafelt, D. W. Satele et al., "Relationship of pass/fail grading and curriculum structure with well-being among preclinical medical students: a multi-institutional study," Academic Medicine, vol. 86, no. 11, pp. 1367-1373, 2011.

[25] L. N. Dyrbye, M. R. Thomas, and T. D. Shanafelt, "Systematic review of depression, anxiety, and other indicators of psychological distress among U.S. and Canadian medical students," Academic Medicine, vol. 81, no. 4, pp. 354-373, 2006.

[26] W. Glover, "Work-related strain injuries in physiotherapists," Physiotherapy, vol. 88, no. 6, pp. 364-372, 2002.

[27] J. E. Cromie, V. J. Robertson, and M. O. Best, "Work-related musculoskeletal disorders and the culture of physical therapy," Physical Therapy, vol. 82, no. 5, pp. 459-472, 2002. 
[28] W. Glover, A. McGregor, C. Sullivan, and J. Hague, "Workrelated musculoskeletal disorders affecting members of the chartered society of physiotherapy," Physiotherapy, vol. 91, no. 3, pp. 138-147, 2005.

[29] Australian Bureau of Statistics, 4326.0 National Survey of Mental Health and Wellbeing: Summary of Results, Australian Bureau of Statistics, 2007.

[30] K. Kjeldstadli, R. Tyssen, A. Finset et al., "Life satisfaction and resilience in medical school: A six-year longitudinal, nationwide and comparative study," BMC Medical Education, vol. 6, article no. 48, 2006.

[31] W. W. S. Mak, I. S. W. Ng, and C. C. Y. Wong, "Resilience: enhancing well-being through the positive cognitive triad," Journal of Counseling Psychology, vol. 58, no. 4, pp. 610-617, 2011.

[32] L. W. Roberts, T. D. Warner, C. Lyketsos, E. Frank, L. Ganzini, and D. Carter, "Perceptions of academic vulnerability associated with personal illness: A study of 1,027 students at nine medical schools," Comprehensive Psychiatry, vol. 42, no. 1, pp. 1-15, 2001.

[33] R. D. Schweitzer, "Problems and awareness of support services among students at an urban Australian university," Journal of American College Health, vol. 45, no. 2, pp. 73-77, 1996. 

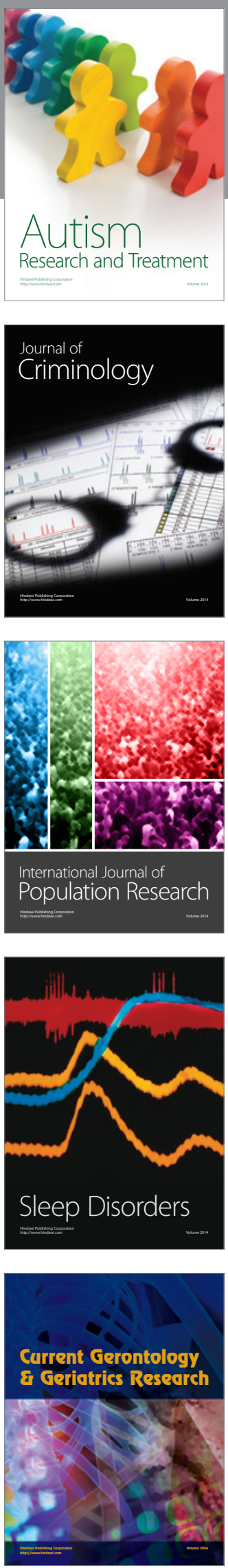
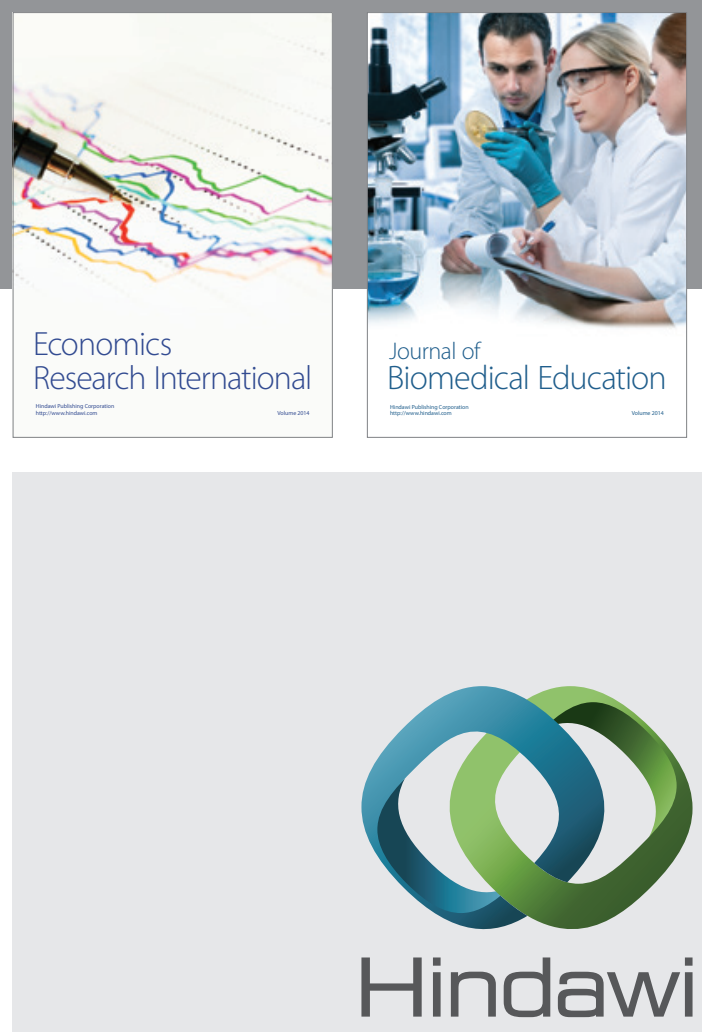

Submit your manuscripts at

http://www.hindawi.com
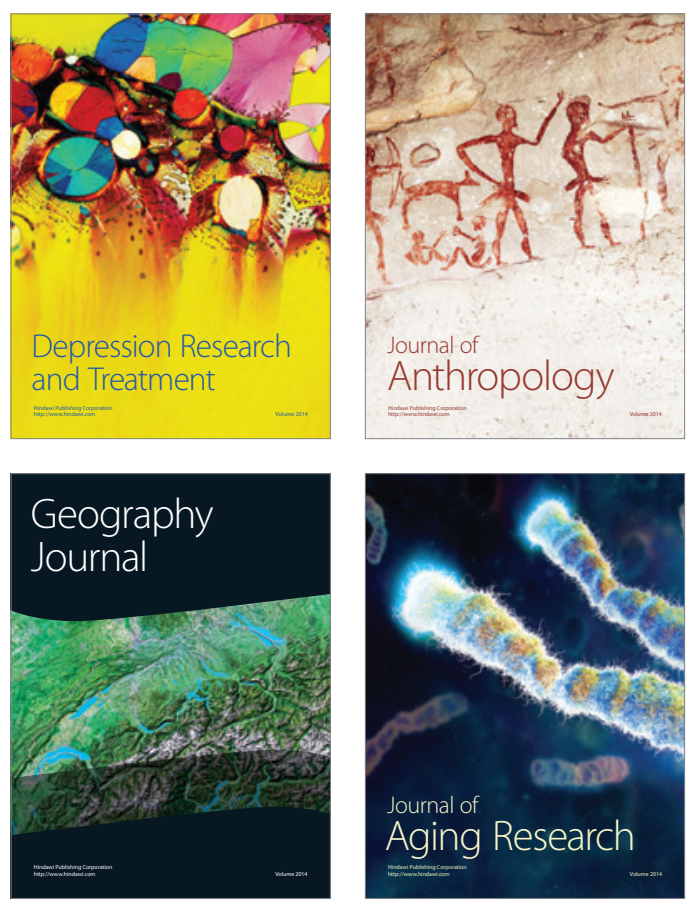
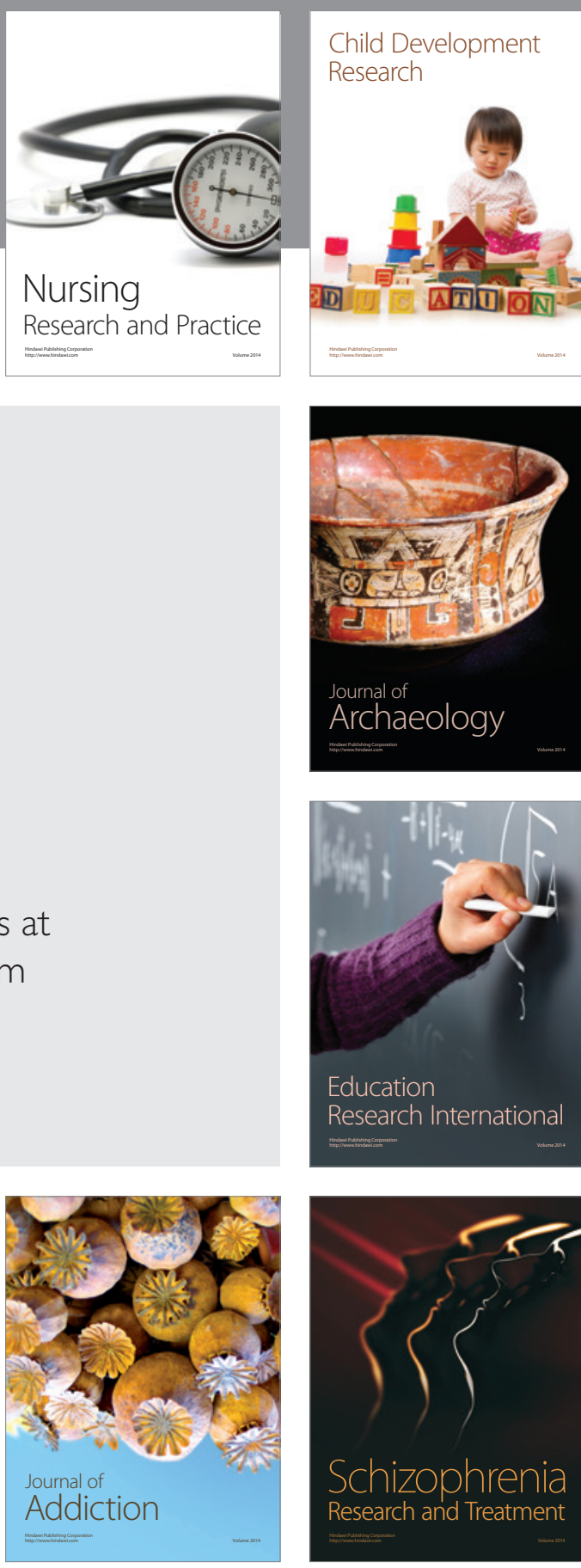

(D)
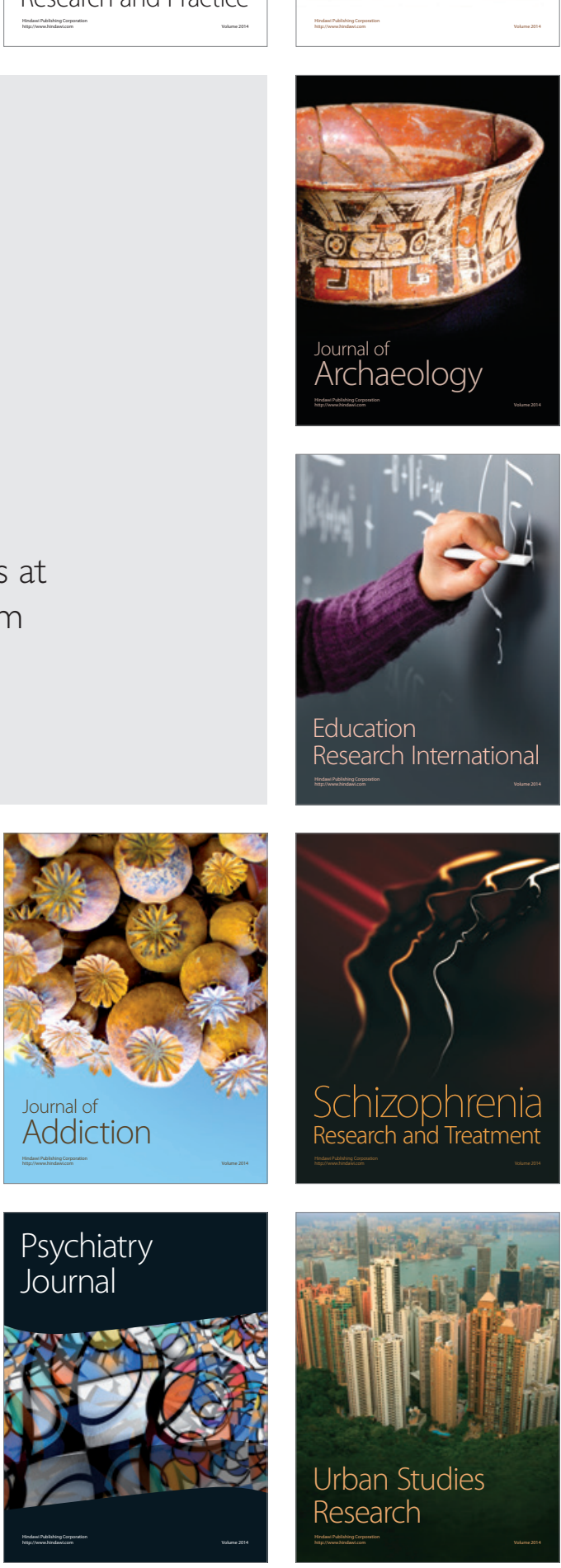